\title{
LETTERS
}

Send your letters to the editor, British Dental Journal, 64 Wimpole Street, London W1G 8YS or by email tobdj@bda.org

Priority will be given to letters less than 500 words long. Letters should be typed. Authors must sign the letter, which may be edited for reasons of space

\section{Phantom bite}

Sir, Messrs Jagger and Korszun (BDJ 2004, 197:241) have drawn attention to an interesting and puzzling problem and given us a penetratingly accurate description of the signs and symptoms of this baffling condition. I am treating three such cases at the moment and may be able to add some additional characteristics and possibly an explanation.

I think that the following additional features will often be present.

1. An increased freeway space often exceeding five millimetres.

2. A raised muscle tone frequently accompanied with intermittent clenching. 3. They often complain that there does not seem to be room for their tongue.

4. They say that they have to hold their jaw in a certain position - usually forward - for it to feel comfortable.

5. They will frequently say that their jaws do not seem to fit together.

6. Sometimes they have acute episodes of pain in an individual tooth (pulpal and periodontal) and may demand to have this tooth extracted only to find the pain persists in an adjacent tooth.

7. They will frequently store a thick wedge of tongue in between their teeth and on examination marked scalloping will be seen along the sides of the tongue.

8. Although they normally maintain a conscious lip seal, they posture with their lips 3 to $4 \mathrm{~mm}$ apart when fully relaxed. 9. On careful examination, their maxilla and mandible will be found to be retruded when compared with a patient with a full dentition and well aligned teeth (Figure 1).

In my view, the aetiology is a lack of tongue to palate contact which allows the maxilla to drop back. Deprived of space the tongue tends to rest between the teeth for long periods interfering with the dental interdigitation. As a result these patients often have premature contacts which do not respond to equilibration. They clearly have difficulty in explaining their problems although many of them are highly intelligent and if the clinicians are unable to diagnose an obvious cause they are at risk of being labelled irrational.
My personal recommendation for treatment is to train the patient to try and keep their teeth in light contact with their tongue resting against their palate.

Unfortunately the tongue often 'feels' too large to fit in the vault but the size of the tongue is to a large extent the result of its hyperactivity.

This may be assisted if the maxillary arch is enlarged and/or moved forward. Bite splints may help to relieve pain in the short term but discomfort is likely to return later.

J. Mew

Sussex

doi: 10.1038/sj.bdj.4811930

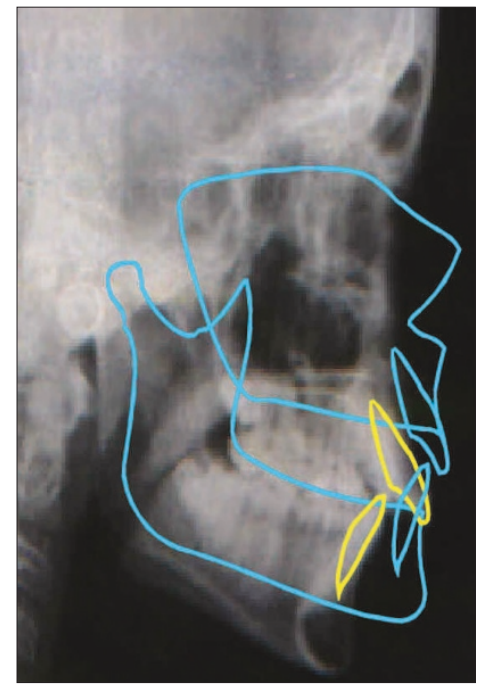

Figure 1

\section{Indemnity insurance}

Sir, I believe the news article on indemnity insurance (BDJ 2004, 197:523) is incorrect. 'Currently... the GDC lays down in its professional standards that a registered dentist must have indemnity insurance'. This is not true - the GDC guidance notes do not presently include the word 'insurance'.

I am presently in correspondence with the GDC on this matter as it is my view that the use of the word 'indemnity' in the professional standard content is also misleading as the GDC recognises the discretionary professional negligence services offered by some insurance companies for example.

The meaning of the word 'indemnity' is not open to misinterpretation and by definition involves some form of legal contract or contingent protection against loss or damage which of course discretionary cover does not.

The Department of Health recognises this and wishes to remove all possible doubt. The news item is timely as it looks as though indemnity insurance will be very much the order of the day from as soon as 1 January 2005 and dentists will need to review their arrangements very soon.

If a dentist renews their current arrangements for the New Year that fall outside the new Section 60 Order amending the Dentists Act, he or she will be practising unlawfully and open to prosecution and removal from the Dental Register.

The profession should not underestimate the significance of what lies ahead as the results could be very costly and stressful for the majority of GDPs who presently have discretionary professional negligence arrangements in place!

\section{N. J. Knott Wiltshire}

CDN Morris, legal advisor to the BDJ responds: I refer to the recent news item (BDJ 2004 197:523) and to N Knott's letter and thought it might be helpful to summarise the current legal position.

The GDC's Guidance to Dentists on Professional and Personal Conduct 'Maintaining Standards' at paragraph 1.2 requires that 'A dentist involved in advising or treating patients must either hold appropriate membership of a defence organisation or otherwise be indemnified against claims for professional negligence. .... A lack of appropriate defence organisation membership or adequate indemnity cover, which includes professional and legal advice, would almost certainly lead to a charge of Serious Professional Misconduct.'

Thus at the present time appropriate membership of a defence organisation or adequate indemnity cover is acceptable to the GDC. The Dentists Act 1984 is silent as 
to the need for dentists to hold indemnity cover/MDO membership and it is not a requirement of registration with the General Dental Council. Wide ranging amendments are currently being proposed to the Dentists Act (by way of a Section 60 Order) to include possible changes to the present indemnity position.

As drafted for the purposes of consultation, the new legislation would require that, to successfully register with the GDC, the registrant/applicant must hold '... a valid policy of insurance which covers him against any liability which may arise in carrying out work in the United Kingdom as a dentist or in a profession complementary to dentistry.'

Further, the individual concerned would need to be able to supply the GDC on either application for registration or renewal, with evidence sufficient to satisfy the Council that he has such a policy and that it is current. Failure to comply with these requirements may be treated as misconduct.

The Department of Health's consultation paper 'Strengthening the General Dental Council' (dated July 2004) can be found on their website www.dh.gov.uk. The Section 60 Order as presently drafted is an enclosure to it. The consultation period closed at the end of October. The GDC have provided a detailed response to the consultation paper (dated 29 October 2004) which can be found on their website www.gdc-uk.org.

Other organisations have also provided comments. The GDC make a number of representations about the draft Order on the issue of indemnity.

These include reference to debate across the healthcare sector about the relative merits of insurance as compared with the traditional model of indemnity provided by mutual organisations.

The GDC request that the Order be redrafted to allow the Council to determine what is and is not acceptable cover. The Council also give their view that the requirement for each registrant to have a valid policy of insurance would be inappropriate, recognising that the indemnity requirements for different groups of registrants vary widely.
The Department of Health are currently reviewing the responses they have received to the consultation paper and draft Order, which may, of course, lead to amendments.

It is intended that the Order will be published in its final format in March 2005 with a view to seeking Parliamentary approval shortly thereafter.

Secondary legislation will then be required to amend various Regulations and GDC ethical guidance, which will doubtless take several months. Thus, it may be somewhat premature to suggest that indemnity insurance will be very much the order of the day from as soon as 1 January 2005.

Dr Knott does, however, raise an important issue, being that practitioners will need to keep a close eye upon developments in this field and ensure that their indemnity/defence organisation cover arrangements comply with any new legislation. Doubtless any changes to the status quo will receive considerable publicity prior to coming into force.

doi: 10.1038/sj.bdj.4811932

\section{Pain relief}

Sir, I would like to take the opportunity to bring to the attention of your readers a procedure that might be useful in a busy general dental practice. This procedure is useful for pain relief if a properly root canal filled tooth or a tooth with a post crown starts to cause pain, especially if a re-root canal treatment or apicectomy is planned. The acute treatment could be in raising a simple mucoperiosteal flap then drilling a small cavity where the tip of the root is expected with a micromotor.

That will relieve the pressure and let any pus present drain from the cavity. The flap is then sutured back. An apicectomy or any other definitive treatment can follow later once the symptoms are relieved.

This also allows a general dental practitioner, who may not wish to undertake a formal apicectomy, to achieve pain control rapidly. I believe patients will very much appreciate such pain control. Y. Zanganah

By email

doi: 10.1038/sj.bdj.4811931 